\title{
A Rare Case of Sequelae of Iatrogenic Volkmann Syndrome Successfully Treated by Shortening of the Two Bones of the Forearm
}

\author{
IBRAHIMA Farikou*1,2, EGBEARONG ASHU MBENG ${ }^{1}$, MBO AMVENE Jérémie ${ }^{2}$, NGAROUA David ${ }^{2}$ and HANDY EONE \\ Daniel $^{1}$
}

${ }^{1}$ Faculty of Medicine and Biomedical Sciences of Yaoundé, Cameroon

${ }^{2}$ Faculty of Medicine and Biomedical Sciences of Garoua, Cameroon

*Corresponding author: Ibrahima Farikou, Faculty of Medicine and Biomedical Sciences of Yaoundé, and Garoua, Cameroon; Email: ifarikou@hotmail.com

Received: November 16, 2019; Accepted: November 21, 2019; Published: November 27, 2019.

\begin{abstract}
Introduction: Volkmann's syndrome, usually due to fracture of the forearm bones, is a condition that requires emergency fasciotomy. But the case that we report today is unusual: an ischemic retraction installed following immobilization of the forearm by a traditional splint without any evidence of fracture. To date, at the height of our knowledge, no similar case has been reported. The aim of this work was to show that the shortening of both bones realized is an attractive alternative to treat severe sequelae of this syndrome in our context.

Case Report: He is a 9-year-old boy who fell from games and had a closed trauma to his left forearm. At 3 months post-traumatic when we saw him, we note serious sequelae already installed consisting of wrist flexum and invincible claws fingers. The radiography realized a posteriori was normal. The preoperative electromyogram concludes that the 3 nerves of the forearm have been affected. We performed a shortening of the 2 bones of the forearm with contention by 2 intramedullary pins completed by a plaster splint to maintain the reduction obtained intraoperatively. The radio-clinical and electromyographic control post-operative showed a clear improvement anatomical and functional.
\end{abstract}

Discussion and Conclusion: The incidence of Volkmann syndrome in upper limb fractures is estimated at $1 \%$. The absence of fractures would promote the diagnostic delay. In this case, two contributing factors were added, a fracture-free contusion treated with a traditional constrictive splint aggravating ischemia. This case of Volkmann syndrome, due in part to ignorance but treated favorably, challenges us in a cultural context where the traditional healer paradoxically enjoys great confidence. Beyond stigma, it is important for us to project the bases of a collaboration in the interest of the patients.

Keywords: Africa, Sequelae, Treatment, Volkmann Syndrome

\section{Introduction}

The ischemic retraction syndrome of the hand flexors described by Volkmann in 1881 results from a conflict between the inextensible muscular chambers and the extensible forearm muscles. It is a surgical emergency that requires rapid release of superficial but sometimes deep muscle compartments. It is most often a diaphyseal fracture of the 2 bones of the forearm or a distal fracture of the radius. This syndrome occurs even more often in supra-condylar fractures of the child's elbow associated with vascular injury. But the case we report today is unusual: it is an ischemic retraction that has occurred following immobilization of the forearm by a traditional healer without any radiological evidence of a fracture. To date, at the best of our knowledge, no similar case has been reported.

\section{Case Report}

The 9-year-old boy, who fell to the games, had a closed trauma to his left forearm and was driven, as is often the case in the hinterland, to a traditional healer. He was then immobilized by a splint of braided bamboo or millet stems as is often the case in our practice conditions (Figure 1). No X-ray was performed to confirm the existence of broken bones in the injured forearm. Faced with the appearance of edema, cutaneous lesions like phlyctens, cutaneous wounds, retraction and paralysis of the fingers, the splint would have been removed but it was too late because the compartments syndrome was already constituted with irreversible sequelae already installed. Unfortunately, this type of complications is not isolated in our environment. We also performed a necrotic finger amputation treated under the same conditions (Figure 2). We received it after about 3 months post-traumatic period. He then had severe sequelae consisting of wrist flexum, severe invincible fingers claw with Metacarpophalangeal (MP) hyper-extension, hyperflexion of Proximal Interphalangeal (PIP) and irreducible Distal Interphalangeal (DIP) joints (Figure 3). The radiography performed on site before the consultation shows that there was no bone lesion that required external restraint (Figure 4).

The compared Electromyogram (EMG) requested preoperatively concludes to an attack of the 3 nerves of the forearm (medial $>$ cubital $>$ radial) with signs of Wallerian degeneration. The involvement is 
more severe on the left median and the functional prognosis on the physiological basis of this nerve is considered pour. On the left ulnar and the radial nerves, the lesion is less severe with a more favorable recovery prognosis according to the neurologist who performed this examination. We intervened to try a lengthening of the flexors including the short and long palmar which a priori had no effect on the correction of retractions. We resolved to shorten proximal metaphysis of the 2 bones of the forearm and to achieve the internal fixation by 1 respective intramedullary pin at the level of the radius and the ulna. The intraoperative examination shows a good reduction of the retractions, we obtain a passive extension of the wrist, a passive flexion of the MP, an extension, at the limit of the position of function of the PIP and DIP joints of $20^{\circ}$ and $30^{\circ}$ respectively. We set up a plaster cast brace to sustain this reduction obtained to keep for 6 weeks. The radiographic assessment of postoperative control is satisfactory (Figure 5). We had the plaster removed and prescribed re-education of the wrist and fingers of the hand. At the last consultation, the function recovered from the wrist and the hand was satisfactory (Figure 6).

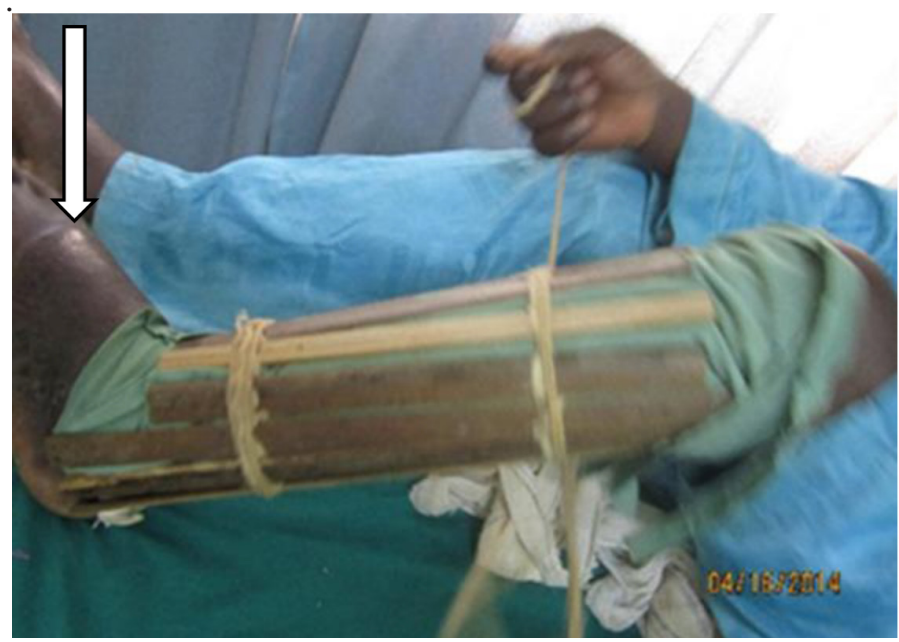

Figure 1. An example of a traditional splint used to immobilize a fracture of the 2 bones of the leg: we can see the formation of an edema of the foot upstream (white arrow).

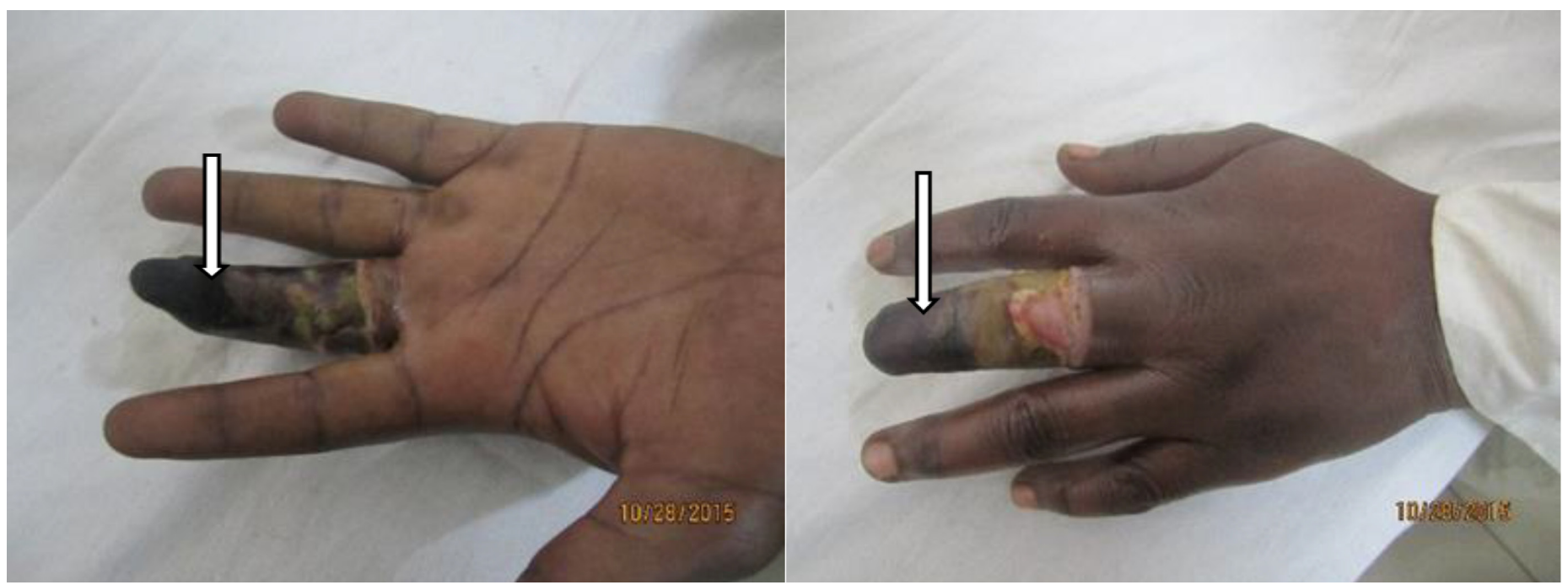

Figure 2. Ischemic necrosis on contusion without fracture of the 3rd finger treated by traditional splint (white arrows): the finger was amputated. 


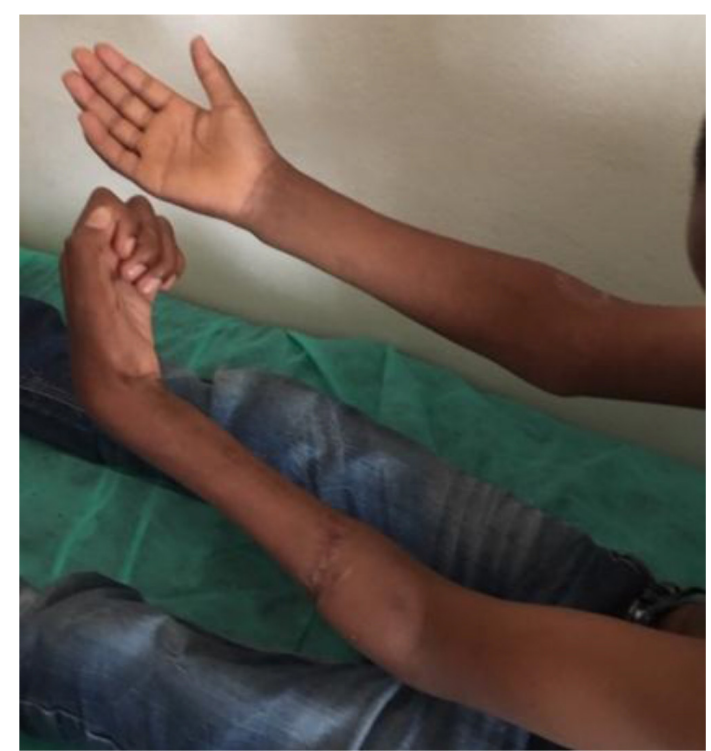

Figure 3. Preoperative appearance of sequelae: scars of skin lesions, wrist flexion, and extension of metacarpophalangeal joints and hyperflexion of proximal interphalangeal joints.

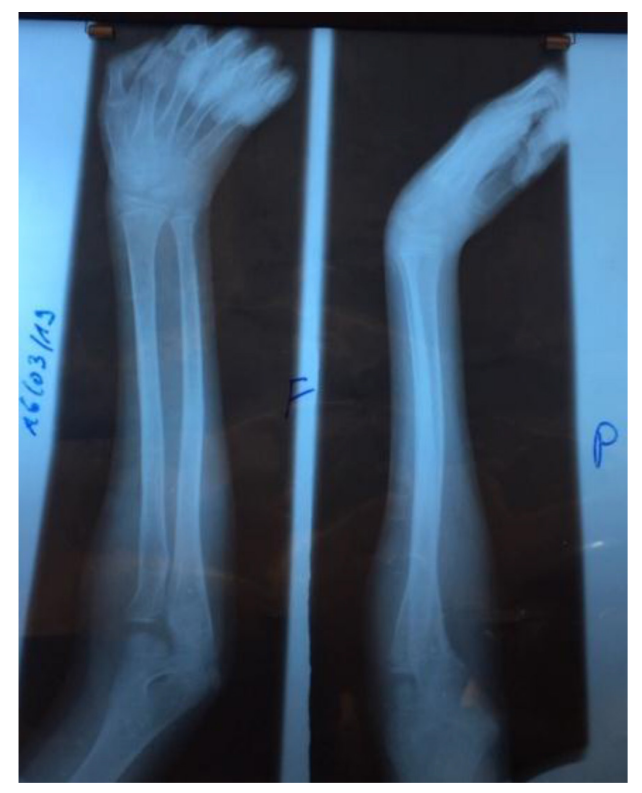

Figure 4. The radiograph performed "a posteriori" shows no fracture lesion that would have required immobilization.

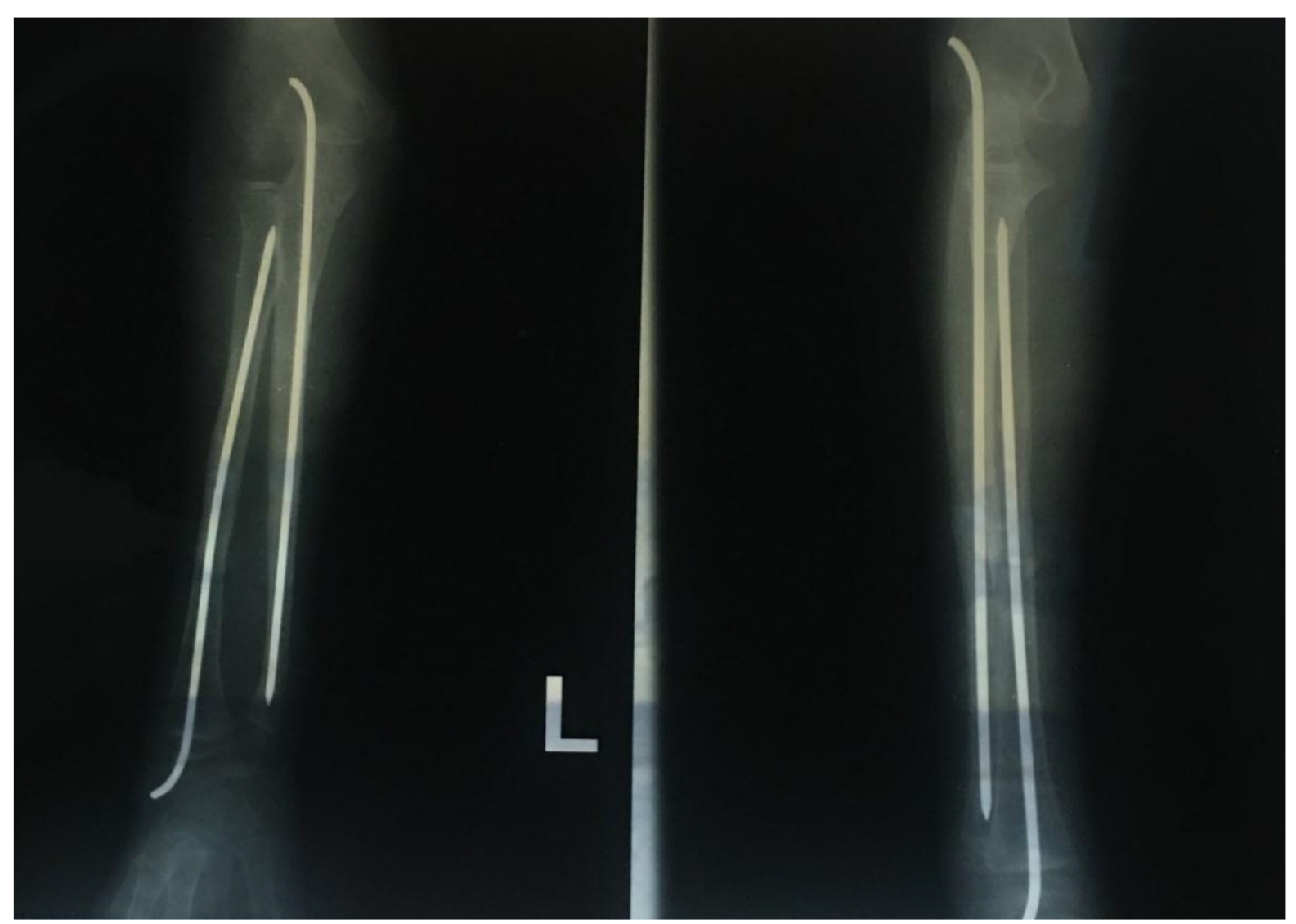

Figure 5. The postoperative X-Ray (D 117) showing the shortening of the proximal metaphysis of the 2 bones and contention with intramedullary pins with onset of consolidation. 

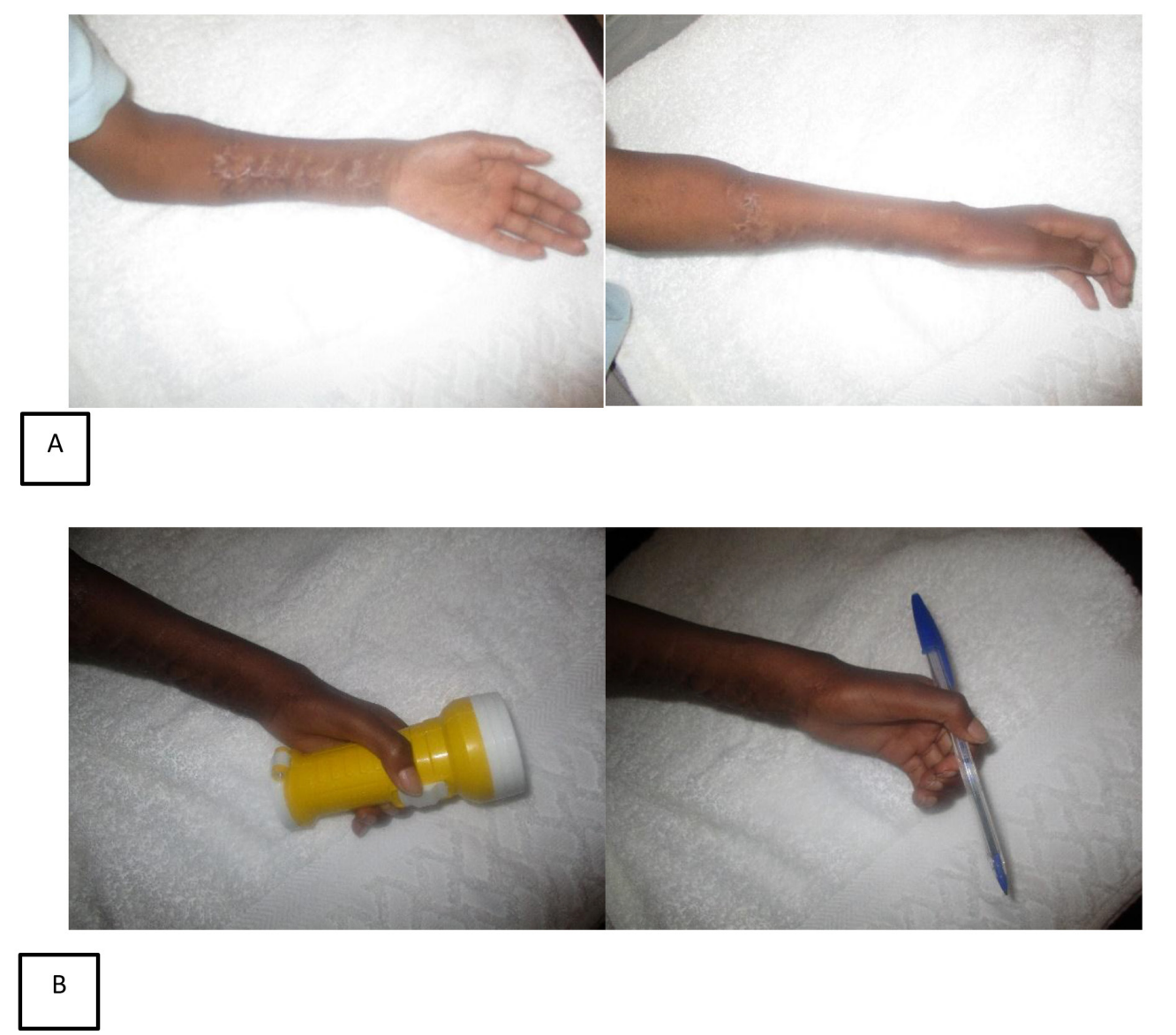

Figure 6. The anatomical (A) and functional (B) result is quite satisfactory especially for large (large objects) and fine (finer objects) pollici-digital grip.

\section{Discussion}

The Volkmann syndrome, ischemic retraction of flexors, first described in 1881 by the same one who bears his name, is a relatively rare surgical emergency [1]. This syndrome is most often associated with trauma including fractures, penetrating wounds, contusion of soft tissues, animal or insect bites, infections, reperfusion ischemia or external compression by dressing or plaster, burns or crushing injuries. The incidence of occurrence in upper limb fractures is estimated at $1 \%$ [2]. In this case we can think that there are two contributing factors, a fracture-free bruise treated by traditional constrictive splint worsening ischemia: "a chicotte on an abscess" according to a well-known Fulani saying. At this stage, an alcoholic dressing renewed 2 or 3 times a day and nonsteroidal anti-inflammatory drugs and especially a regular follow-up for a few days would have been enough. It should be noted that the absence of a fracture has been considered by some authors as a factor delaying the diagnosis and worsening the prognosis $[3,4]$. The fractures of the child likely to lead to the syndrome of the lodges of the forearm are essentially the diaphyseal fractures of the 2 bones of the forearm and supra-condylar fractures of the elbow with or without a fracture of the forearm, distal end of the radius in a floating elbow chart $[2,5-7]$. Matsen [8] explained that the lodge syndrome has several vascular mechanisms that all contribute to cell necrosis. The clinical diagnosis is characterized by acute pain, poorly localized, not very sensitive to the usual analgesics and culminating 2 to 6 hours after the trauma. The other signs are a hard swelling, renitence, neuro-vascular disorders like pallor of the extremities, abolition of peripheral pulses, paresthesia and paralysis. Treatment of acute ischemic syndrome requires emergency fasciotomy. In this case it is a severe Volkmann syndrome according to the classification of Tsuge [9], at the stage of serious sequelae attributable to a lack of knowledge by the traditional healer of the anatomophysiological mechanisms at the origin of this syndrome. There is a therapeutic arsenal of interest to the soft tissues and the bone. For the soft tissues extensive excision of infarcted tendons with secondary reconstruction [10-12], Z lengthening of contractured tendons [13], tendon transfer [13] has been proposed. We started by lengthening the flexors but we realized that it had little effect on contracture correction. Surgical techniques concerning the bone, proximal carpectomy [13,14], wrist arthrodesis [13,15]. We preferred the shortening of the 2 forearm bones recommended by Rolands et al [16], Domanasiewicz [17], Pavanini and Volpe [18]. All these methods have their disadvantages, in particular the shortening is criticized for having a non-selective effect on both the extensors and the flexors, the worsening of the shortening already favored by ischemia and a high rate of non-union and refracture of the shortening osteotomy site of the 2 forearm bones. It is too early to say about the bone consolidation that we hope will be favorable in children in this 
case. However, the first current anatomical and functional results are satisfactory and encouraging.

\section{Conclusion}

This case of Volkmann syndrome and other similar pathologies that we encounter in our conditions of practice but unimaginable elsewhere in the West, due mainly to ignorance challenge us in a cultural context where however this same traditional healer enjoys great confidence. Beyond stigma, it is important for us to lay the foundations of a bridge to approach us in the interest of patients.

\section{List of abbreviations}

Metacarpophalangeal (MP)

Proximal interphalangeal (PIP)

Distal interphalangeal (DIP)

\section{Acknowledgement}

We sincerely thank :

1. Dr SAÏD HAMDJA for his confidence in referring us this little patient;

2. All the Managers and Staff of the Maria Rosa Nsisim Foundation of Ahala I in Yaoundé for creating the conditions for the good conduct of this work.

\section{References}

1. Volkmann R (1881) Die ischaemischen muskellaehmungen und kontrakturen. Centrabl f Chir 51: 801.

2. Grottkau B, Epps H, Di Scala C (2005) Compartment syndrome in children and adolescents. J Pediatr Surg 40: 678-682.

3. Hope M, Mcqueen M (2004) Acute compartment syndrome in the absence of fracture. J Orthop Trauma 18: 220-224.

4. Prasam ML, Ouellette EA (2011) Acute compartment syndrome of the upper extremity. J Am Acad Orthop Surg 19: 49-58.

5. Blakemore L, Cooperman D, Thompson G, Wathey C, Ballock RT (2000) Compartment syndrome in ipsilateral humerus and forearm fractures in children. Clin Orthop Relat Res 376: 32-38.

6. Kalyani B, Fisher B, Roberts C, Giannoudis PV (2011) Compartment syndrome of the forearm: a systematic review. J Hand Surg [Am] 36: 535-543.

7. Yuan P, Pring M, Gaynor T, Mubarak SJ, Newton PO (2004) Compartment syndrome following intramedullary fixation of pediatric forearm fractures. J Pediatr Orthop 24: 370-375.

8. Matsen FA (1975) 3rd Compartmental syndrome. A unifed concept. Clin Orthop Relat Res 113: 8-14.

9. Tsuge K (1964) Treatment of established Volkmann's contracture. J Bone Joint Surg Am 57: 925-929.

10. Seddon H (1964) Volkmann's ischaemia. Br Med J 1: 1587-1592. 11. Seddon HJ (1956) Volkmann's contracture: treatment by excision of the infarct. J Bone Joint Surg $\mathrm{Br}$ 38: 152-174.

11. Tsuge K (1975) Treatment of established Volkmann's contracture. J Bone Joint Surg Am 57: 925-929.

12. Goldner J (1975) Volkmann's ischemic contracture. In: Flynn J (ed.). Hand surgery, New York, Williams \& Wilkins, Pg No: 599-618.

13. Zancolli E (1979) Classifcation of established Volkmann's ischemic contracture and the program for its treatment. In: Zancolli E (ed.). Structural and dynamic bases of hand surgery, Philadelphia, JB Lippincot.

14. Botte MJ, Fronek J, Pedowitz RA, Hoenecke HR Jr, Abrams RA, et al. (1998) Exertional compartment syndrome of the upper extremity. Hand Clin 14: 477-482.

15. Rolands R, Lond M (1905) A case of Volkmann's contracture treated by shortening of the radius and ulna. Lancet 2: 1168-1171.
16. Domanasiewicz A, Jabłecki J, Kocieba R, Syrko M (2008) Modifed Colzi method in the management of established Volkmann contracture--the experience of Trzebnica Limb Replantation Center (preliminary report). Ortop Traumatol Rehabil 10: $12-25$.

17. Pavanini G, Volpe A (1975) [Diaphysary resection using Colzi's method in the treatment of Volkmann's syndrome]. Clin Ortop 26: 287-292.

Citation:

IBRAHIMA F, EGBEARONG ASHU MBENG, MBO AMVENE J NGAROUA D, HANDY EONE D. A Rare Case of Sequelae of Iatrogenic Volkmann Syndrome Successfully Treated by Shortening of the Two Bones of the Forearm. Integr J Orthop Traumatol Volume 2 (5): 1-5. 